\title{
A Study of Heart Rate Recovery Following Exercise in Healthy Young Adult Male
}

\author{
Dr.Jagnyaseni Panda ${ }^{1}$, Dr.Snigdha Prava Mishra ${ }^{2}$, Dr.Bipin Bihari Pradhan ${ }^{3}$ \\ ${ }^{I}$ Tutor, Department of physiology, M.K.C.G Medical College, Berhampur, Odisha. \\ ${ }^{2}$ Associate Professor, Department of physiology, M.K.C.G Medical College, Berhampur, Odisha. \\ ${ }^{3}$ Professor and Head of the department, Department of physiology, M.K.C.G Medical College,Berhampur,
} Odisha.

\begin{abstract}
Exercise has positive chronotropic effect on heart rate and on cessation heart rate returns to preexercise level. A delay in heart rate recovery (HRR) $(\leq 12$ beats in first minute) is considered abnormal and reflects autonomic dysfunction.The present study was taken up to find out the presence of abnormal HRR in normal subjects (Male) and to establish HRR as an independent autonomic marker. For the study 106 healthy young adults (male) were subjected to exercise by Bicycle ergometer till targeted Heart Rate (85\%Maximum Heart Rate(MHR)) was achieved. HRR at the end of 1 minutefollowingcessation of exercise were tabulated. In our study 23(21.7\%) subjects showed Abnormal HRR indicating HRR could be an independent autonomic marker. Keyword-HRR, MHR
\end{abstract}

\section{Introduction:}

Exercise is a common physiological stress used to elicit cardiovascular abnormalities not present at rest and to determine the adequacy of cardiac function ${ }^{1}$. Physiologically it has positive chronotropic effect on heart rate due to sympathetic stimulation and parasympathetic (Vagal) withdrawal (Kluess etal 2000) ${ }^{2}$. On cessation of exercise parasympathetic reactivation and withdrawal of sympathetic activity ultimately leads to return of heart rate towards pre exercise level (Arai etal 1989) ${ }^{3}$.Heart Rate Recovery (HRR) is defined as the change in heart rate from peak exercise to 1 minute following cessation of exercise. Fall in heart rate $\leq 12$ beats after first minute following peak exercise is considered abnormal (Coleetal) ${ }^{4}$.A delay in HRR reflects autonomic dysfunction. Role of Autonomic nervous system in regulation of cardio vascularfunction is well documented.

So the present study was taken up with the objective to find out the presence of abnormal HRR following exercise in healthy young adults (male) and in such cases whether HRR by itself can be an independent autonomic marker.

\section{Materials and Methods}

This prospective study was conducted in the P.G Research Laboratory of Department of Physiology, M.K.C.G Medical College, Berhampur during the period from 2009-11 after due approval from the institutional ethics committee.

For the study healthy young male adults between 17-24 years were included. Cardiac monitor was connected to each subject and Blood Pressure (BP), HeartRate (HR) and Oxygen saturation at rest were recorded. They were subjected to exercise by Bicycle Ergometer with digital display till targeted Heart Rate (85\%MHR) was achieved or appearance of limiting symptoms like(chest discomfort,shortness of breath, dizziness ) whichever was earlier. During exercise continuous recording of heart rate, blood pressure and oxygen saturation were done by cardiac monitor.

At cessation of exercise therecording of HR, BP and oxygen saturation were noted. HRR at the end of 1 minute after cessation of exercise were tabulated and analyzed.

\section{Observation and Analysis}

Total number of 106 healthy young male adults were includes in the study. Their mean BMI was within normal range.

Table 1Anthropometric Parameters of The Study Group

\begin{tabular}{|l|c|}
\hline \multicolumn{1}{|c|}{ Parameters } & $\begin{array}{c}\text { No. of subject (n=106) } \\
\text { (Mean } \pm \text { S.D) }\end{array}$ \\
\hline Age $(\mathrm{yrs})$ & $19.00 \pm 1.24$ \\
\hline Height $(\mathrm{mtr})$ & $1.66 \pm 0.07$ \\
\hline Weight $(\mathrm{Kg})$ & $62.6 \pm 12.22$ \\
\hline B.M.I $\left(\mathrm{kg} / \mathrm{m}^{2}\right)$ & $22.75 \pm 4.04$ \\
\hline
\end{tabular}


Table 2 Pre Exercise Parameters

\begin{tabular}{|c|c|}
\hline Parameters & $\begin{array}{c}\text { No. of Subject (n=106) } \\
\text { (Mean } \pm \text { S.D) }\end{array}$ \\
\hline Heart Rate (beats/min) & $77 \pm 3.86$ \\
\hline $\begin{array}{c}\text { Blood Pressure(mmHg) } \\
\text { Systolic }\end{array}$ & $119 \pm 6.34$ \\
\hline Diastolic & $81 \pm 3.86$ \\
\hline Oxygen Saturation (\%) & $98 \pm 1.25$ \\
\hline
\end{tabular}

Mean heart rate, Blood Pressure both systolic, diastolic and oxygen saturation are within normal range.

Table 3 Exercise Parameters Of The Subjects

$(\mathrm{N}=106)$

\begin{tabular}{|l|c|c|c|}
\hline \multicolumn{1}{|c|}{ Parameters } & $\begin{array}{c}\text { Pre-Exercise } \\
(\text { Mean } \pm \text { S.D) }\end{array}$ & $\begin{array}{c}\text { End of Exercise } \\
\text { (Mean } \pm \text { S.D) }\end{array}$ & $\begin{array}{c}\text { 1 min after cessation of exercise } \\
\text { (Mean } \pm \text { S.D) }\end{array}$ \\
\hline Heart Rate(Beats/Min) & $77 \pm 6.34$ & $163 \pm 9.13$ & $140 \pm 13.58$ \\
\hline Blood Pressure(mmHg) & & & \\
\hline Systolic & $119 \pm 6.34$ & $142 \pm 10.54$ & $136 \pm 8.63$ \\
\hline Diastolic & $81 \pm 3.86$ & $89 \pm 6.32$ & $87 \pm 5.15$ \\
\hline Oxygen Saturation (\%) & $98 \pm 1.25$ & $98 \pm 1.14$ & $99 \pm 0.81$ \\
\hline
\end{tabular}

After exercise mean heart rate increased to $163 \pm 9.13$ and came down to $140 \pm 13.58,1$ minute following cessation of exercise.

Table 4

Exercise Parameters Of Subjects With Abnormal Heart Rate Recovery

$(\mathrm{N}=\mathbf{2 3})$

\begin{tabular}{|l|c|c|c|}
\hline \multicolumn{1}{|c|}{ Parameters } & $\begin{array}{c}\text { Pre-Exercise } \\
\text { (Mean } \pm \text { S.D) }\end{array}$ & $\begin{array}{c}\text { End of Exercise } \\
\text { (Mean } \pm \text { S.D) }\end{array}$ & $\begin{array}{c}\text { 1 min after cessation of } \\
\text { exercise(Mean } \pm \text { S.D) }\end{array}$ \\
\hline Heart Rate(Beats/Min) & $78 \pm 5.75$ & $164 \pm 6.46$ & $155 \pm 5.79$ \\
\hline Blood Pressure(mmHg) & & & $136 \pm 9.43$ \\
\hline Systolic & $119 \pm 8.15$ & $144 \pm 10.45$ & $89 \pm 3.11$ \\
\hline Diastolic & $82 \pm 4.05$ & $92 \pm 4.80$ & $98 \pm 0.65$ \\
\hline Oxygen Saturation (\%) & $98 \pm 1.56$ & $98 \pm 0.79$ & \\
\hline
\end{tabular}

23 male subjects showed abnormal HRR following 1 minute after cessation of exercise, the mean heart rate came down to $155 \pm 5.79$ following 1 minute after cessation of exercise from $164 \pm 6.46$ at end of exercise.

Heart Rate In Subjects With Normal And Abnormal Heart Rate Recovery

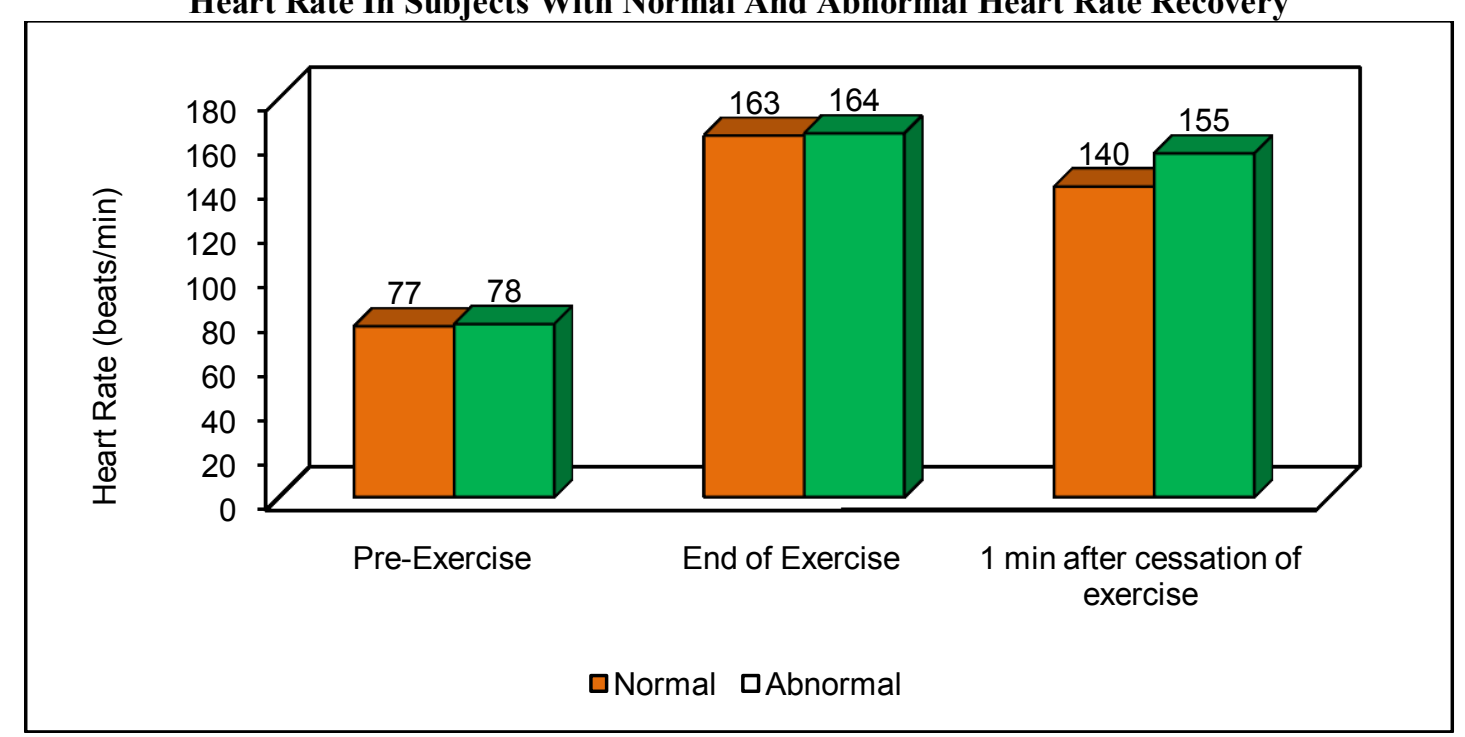




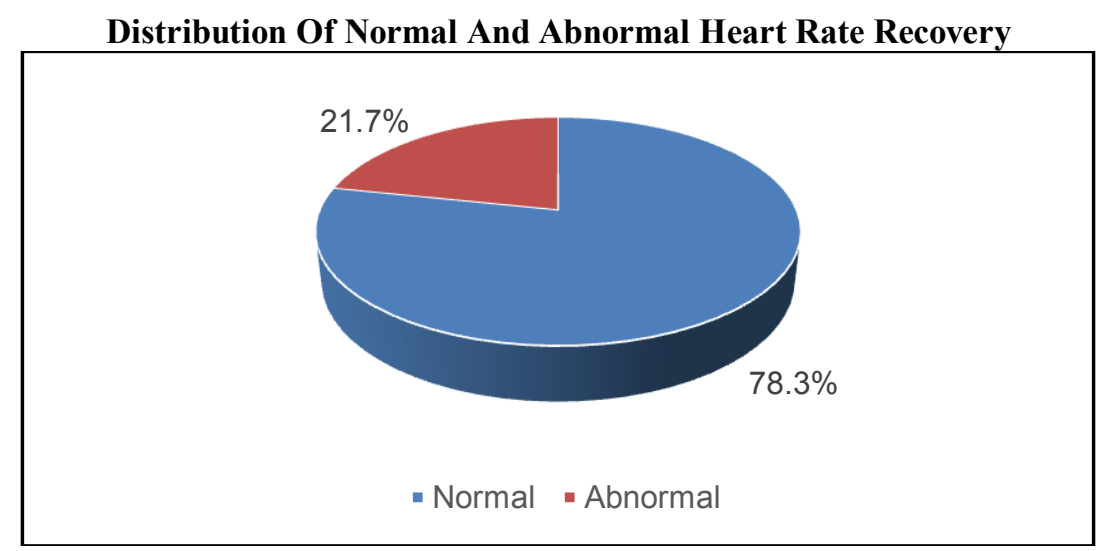

\section{Discussion}

Out of the total 106 healthy male subjects in our study, only 23 showed abnormal HRR ${ }^{4}$. Heart Rate (HR) during dynamic exercise is regulated by a combination of neural, hormonal and intrinsic mechanism. At the onset of exercise the rise in heart rate is thought to be mediated by withdrawal of inhibitory vagal tone. Central command from higher brain centre and input from mechanoreceptors in muscle contribute to this early response. ${ }^{(5,6)}$ At higher heart rate, increase sympathetic out flow to the heart, increased level of circulatory catecholamine and temperature of pacemaker tissue also play a role ${ }^{(7,8,9)}$. Immediately after exercise acceleratory influence from higher brain centre and peripheral nerve reflexesdiminish and heart rate is thought to be primarily regulated by restoration of vagal inhibitory tone $\mathrm{e}^{(10-13)}$

HRR following exercise correlates with vagal tone and a decrease of HRR in the first minute of the exercise is associated with increased mortality. Our study therefore is suggestive of possibility that the HRR following exercise is highly sensitive enough to reflect the autonomic dysfunction due to decreased vagal tone. So, it can be an independent autonomic marker, which is easy to obtain in any clinical set up. Few studies have found out that delay in HRR following exercise, which may be an influence of decrease vagal activity is a powerful predictor of overall mortality, independent of work load, the presence or absence of myocardial perfusion defects ${ }^{14}$. This marker is simple to calculate from data that are already contained in the results of standard exercise tests and may be valuable for the assessment of risk in routine clinical practice.

\section{Summary and Conclusion}

Our study consisting of 106 healthy young male, within age group 17-24 years, was carried out to assess the presence of abnormal HRR following dynamic exercise. Also we aimed at using HRR as an independent autonomic marker. From our study we found out that, $21.70 \%$ of total subjects showed abnormal HRR. Therefore we can conclude that HRR could be an independent variable as a prognostic marker.

\section{References:}

[1]. Hurst's The Heart Valentin Fuster, Richard A Walshs, Robert, A. Harrington, Thirteenth Edition, McGraw Hill Medical, Vol. 1, P. 371.

[2]. Kluss H. A. Wood. R. H. and Welsch. M. A(2000) Vagal modulation of the heart and central hemodynamics during handgrip exercise. American journal of physiology 279, H1648-H1652.

[3]. Arai. Y. Saul. J. P. Albrecht, P. Hartley, L. H, Lilly, L. s, Cohen, R. J. and Colucci, W. S(1989). Modulation of Cardiac autonomic activity during and immediately after exercise. American journal of physiology256, H132-H141.

[4]. Cole CR, Blackstone EH, Pashkow FJ, et al. Heart-rate recovery immediately after exercise as a predictor of mortality . N Engl J Med 1999, 341:1351-1357.

[5]. Maciel BC, L. Gallo, M. Neto, EC Lima Filho, and LB Martin. Autonomic nervous control of the heart rate during dynamic exercise in normal man. Clin. Sc. 71:457:460, 1986.

[6]. Mitchell JH, WC Redon and DI McCloskey. Reflex effect on circulation and respiration for contracting skeletal muscle. Am. J. Physiol, 233(Heart Circ. Physiol 2):H374-H378, 1977.

[7]. Lamb DL. The physiology of aerobic endurance. In: Physiology of exercise ( $2^{\text {nd }}$ ed), New York, Macmillan, 1984, P. 137-143.

[8]. Robinson BF, SE Epstin, GD Beiser and E. Braunwald. Control of Heart rate by the autonomic nerves system. Circ. Res. 19:400411, 1966.

[9]. Von Euler, US. Sympatho-adrenal activity in physical exercise. Med. Sci. Sports, 6:165-173, 1973

[10]. Blomqvist CG and B. Saltin. Cardiovascular adaptations to physical training. Annu Rev. Physiol. 45:169-189, 1983.

[11]. Savin WM, DM Davidson and Wl Haskell. Autonomic contribution to heart rate recovery from exercise in humans. J. Appl. Physiol, 53:1572-1576, 1982.

[12]. Savin WM, WM Haskell, JS Schroeder and EB Stinson. Cardiorespiratory responses of cardiac transplanting patients to graded, symptom limited exercise. Circulation 64:55-60, 1980.

[13]. Scheuer J. and CM Tipton. Cardiovascular adaptations to physical Training. Annu Rev Physiol, 39:221-251, 1976.

[14]. Christopher R, Cole MD, Eugene H, Black Stone MD, Fredric J, Pshkow MD, Claire E, Snader MA and Michael Laucher MD. Heart rate recovery immediately after exercise as a predictor of mortality, Vol. 341:1351-1357, October, 28, 1999. 